3. Is the tooth as good as the original one whose place it fills? No; and it will be remembered that I had it upon good dental authority that a better result than mine was at two months after the operation cannot be had.

Buckhannon, W. Va., March 17, I888.

\section{THE NECESSITY FOR INSPECTION OF ANIMALS REQUIRED FOR FOOD.}

Read in the Section on State Medicine, at the Thirty-Eighth Annual Meeting of the American Medical Association, Fune, 1887

BY CARL II. HORSCH, M.D., OF DOVER, N. H.

Among the number of persons who have made efforts to prevent the eating of diseased animal food, Moses was the first well-known. The commands in the Talmud are:

"The animal shall be killed with a sharp knife and three cuts. If the knife has a jagged edge, or the animal breaks a leg when falling at the time of butchering, the meat is condemed.

"To eat no meat from a diseased animal;

"From an animal that has died suffering with tympanites;

"Animals which have jaw worm;

"Lameness from any cause;

"No meat from calves under eight days old;

"From sheep suffering with tetter;

"Diseases of the lungs, abnormal formations, more lobes on one side than the other (on the right $3,5,7$, on the left $4,6,8$,) adhesions, indurations, patches, water-blisters, matter in the vessels, if the lungs are flabby, dry, black, yellow, whitish, fleshy, or coagulations of dark, stringy blood are fouud in the vessels.

"No suppuration, or other diseases of the liver, spleen, or kidneys.

"No sharp things in the stomach, which perforated the lining of the walls, and have pus on them.

"Meat from healthy animals, and where the large vessels have been cut out is called Kausher."

Regarding eating pork and no fish without scales, this was most likely a dietetic regimen for the condition of the Israelites in tropical regions, and against prevailing diseases such as leprosy. It would be well if the rational parts of these commands were obeyed by all nations.

Dr. Most says: "Only healthy animals should be butchered and their meat used for food. The signs of health are: The animal moves around and appears lively; by applying gentle pressure on the back it does not bend the ears or tail; the eyes look clear and bright; the body is well formed and nourished; rumination of the cud is carried on well, no saliva flowing from the mouth; no blisters or pustules on the mucous membrane; breath is normal. no cough, groaning or gasping; the skin is not tightly grown to the body, is free from pustules, scurf, or scales; temperature normal; hair glossy. After skinning the animal we should find no boils, tumors, pustules nor black spots; the meat should be firm and has the characteristic fresh smell.
"Meat is not fit to eat from too old, too young, or from sick animals. Such meat is hard, tough, or soft, pale, watery or greasy, and the fat is soft, green or yellow. On opening the chest of healthy animals there is no putrid, bad-smelling exudations, no white patches or ulcers, no difference in color, and no disease in the surroundings of the lungs. In the stomach and bowels we find no red spots, soft, gray, black places, no dry, dark looking remains of food.

"The best meat comes from healthy animals of middle age. The appropriate age to fatten oxen is from 5 to 8 years old. Calves should be at least 3 or 4 weeks old, dropped the umbilical cord, and have lost the milk teeth. Veal and mutton should be kept from two to four days, beef and pork from four to eight, venison from four to ten, and fowls from two to four days. Fish should be cooked soon after they are killed.

"The meat of animals which have been driven fast before slaughtering is darker and heavier, contains more blood and decomposes sooner. The meat of animals killed by lightning is not fit for food. Some butchers inflate mutton to make it look plump, but such meat may contain the fetid breath of some person."

Dr. Most cites the following cases:

A man contracted a malignant fever and died, after salting meat from an ox which had been sick with murrain (Vieh-seuche). A family died after eating the meat of a hog which had been sick with angina (Braüne). In Marburg, Stiermark, several persons died of hydrophobia, who had been eating meat from cattle which had been bitten by a mad dog. ${ }^{2}$

In 1869 I was called to see a patient in Dover,N.H. The gentleman was 70 years old, a man of regular habits, and had been the most of his life healthy and strong, until March, I 869, when two of the lymphatic glands on the neck and several of the inguinal glands became enlarged. After examination and deduction of other diseases I diagnosed scrofulosis. The patient was a reliable, intelligent observer, and stated that he never before in his life had any signs of that disease and that there had been nocase of scrofulosis on either his father's or mother's side. I afterwards ascertained that the butcher of whom my friend bought his meat had slaughtered and sold the meat of an ox which had a large swelling near one of his ears; the person who saw the animal called it "a wolf." This was a case in which I could find no other cause than diseased meat.

Two years ago a farmer brought a fat, good looking turkey to my house. While preparing it for cooking my wife found a very large liver, with white patches of the size of a cent throughout the tissue. On further examination I found fatty degeneration of the liver, and decided that the meat of that fowl would be better relished by the worms.

Glanders, hydrophobia, malignant pustules, splenic fever, tuberculosis, trichinæ and other diseases are dangerous and communicable from animals to man.

1 Ausführliche Encyklopädia der gesammten Staatsarzneikunde, von George Friedrich Most. Doctor der Philosophie, Medicin, Chirurgie und Geburtshülfe, etc., etc. 
The bare thought that we are liable to eat the meat of diseased animals causes the strongest aversion and there is certainly danger of contracting diseases thereby.

Dr. D. S. Salmon, Chief of the Bureau of Animal Industry, in answer to a letter from Mr. J. W. Bartlett, Dover, N. H., wrote:

Washington, D. C., Feb. I2, 1887.

In reply to your communication of the $9^{\text {th }}$ inst., I would state that so far as I know there is no systematic and complete inspection of the cattle killed for beef in any State of the Union. Many states have beef inspectors, but as a rule they do not inspect all the beef, and in most cases do not see the animal before it is slaughtered, or the internal organs when they are removed. They simply look at the beef after the carcass is dressed. Such an inspection is not sufficient to discover all cases of disease for which carcasses should be condemned. Very respectfully,

(Signed), D. E. SAlmon, Chief of Bureau.

In an interview with Dr. S. H. Durgin, of the city Board of Health, Boston, Mass., Mr. Bartlett ascertained that the city has had an inspection of cattle and meat three years. "All the cattle are inspected two or three days before the slaughtering, and the Inspector sees the animals killed. If he suspects any disease he inspects the heart, lungs, liver, etc., but does not make a general practice thereof. In case the animal shows evident signs of disease before killing, it is slaughtered in the rendering-house away from all healthy animals. All disputed cases are referred to the city Board of Health, whose decision is final.

Dr. Durgin stated that a large amount of tuberculosis in cattle, especially in cows, has been found."

In order to provide a better safeguard against the use and sale of diseased meat, every animal should be inspected by competent persons before slaughtering, and the internal organs thoroughly examined afterward.

The members of the American Medical Association, Medical Societies, National Board of Heath, American Public Health Association, State and local Boards of Health, every well meaning medical practitioner and citizen ought to see the importance of such a sanitary measure, and make an effort to impress it on the minds of their Representatives to Congress, State Legislatures, County, City and Town officers, that it is for their own safety and for that of over 5I,000,000 of inhabitants, and thousands of persons travelling in this country, to pass laws and make appropriations for such protection, and to give the able members of $85,67 \mathrm{I}$ physicians, and of the veterinary surgeons a chance to carry out that very much needed part of State Medicine.

\section{A CASE OF ECLAMPSIA, WITH ALBUMINURIA;} TREATMENT.

BY J. H. BENNETT, M.D., OF WaUseon, ohio.

Mrs. H., æt. 35, multipara, was taken with convulsions at end of eighth month of pregnancy. At 4 o'clock in the morning of September 28 her husband was aroused from sleep by the convulsive action and labored breathing of his wife. I was called immedi- ately and found patient in a comatose state; face and hands and, in fact, the whole body, odematous to an uncommon extent. Being naturally plethoric, I 6 ounces of blood were taken from the arm, followed by ro grs. of calomel combined with $\mathrm{x} / 4 \mathrm{gr}$. of elaterium. This procedure and treatment had a very happy effect in controlling the alarming symptoms. Elaterium was continued in $\frac{1}{5}$-gr. doses administered every three hours, with 60 grs. of cream of tartar, until thorough watery stools were secured, which reduced the odematous condition almost entirely.

Believing that urea decomposing in the blood causes the phenomena of eclampsia, benzoic acid was administered (after the thorough watery evacuations were brought about), in 8-gr. doses every three hours until the patient became conscious, after which the same treatment was continued, with the addition of wine of colchicum and guaiacum.

As soon as the patient was able to do so, the knee and chest position was adopted and maintained at times when her strength would allow of its use, thereby relieving in a mechanical way the pressure caused by the weight of the gravid uterus upon the renal circulation. The urine was frequently tested for albumin, and for the first few days the quantity was enormous, the test-tube showing that two-thirds to three-fourths of its contents was albuminous on reaching the boiling point.

The bowels were kept well open with occasional doses of cream of tartar and elaterium, with a view of reducing the work of the kidneys. Her diet during this time was a generous and nourishing one. Labor commenced in about thirty days from the time she was taken with convulsions, which terminated very pleasantly in every particular to both mother and child in about two hours from its beginning.

Considering the case from first to last, and especially the unfavorable circumstance of not being able to see my patient until taken with convulsions, and the happy results of treatment adopted, and finally the short and easy labor, leaving mother and child in excellent condition, impressed me as being worthy of more than ordinary consideration. The only addition to the treatment mentioned was an occasional dose of bromide of potash and hydrate of chloral to secure rest at night.

After an experience of nearly forty years in the practice of medicine, and in the successful treatment of puerperal convulsions when this method was followed; varying, of course, according to condition of patient and indications observed, leads me to firmly believe in its efficacy and importance.

There are five important indications to meet, as a general rule: First, to relieve the congested brain and venous system by bloodletting; second, to relieve the odematous condition usually present, by administering drastic cathartics; third, to neutralize the carbonate of ammonia present in the blood by use of benzoic acid; fourth, to eliminate from the system urea, by the use of colchicum and guaiacum, thereby preventing its decomposition; fffth, knee and chest position, where it can be done, to relieve in a mechanical way the renal circulation.

Wauseon, Ohio. 